\title{
Article \\ Factors Associated with Financial Security, Food Security and Quality of Daily Lives of Residents in Nigeria during the First Wave of the COVID-19 Pandemic
}

\author{
Morenike Oluwatoyin Folayan ${ }^{1,2, * \mathbb{D}}$, Olanrewaju Ibigbami ${ }^{1,3} \mathbb{D}$, Maha El Tantawi ${ }^{1,4} \mathbb{D}^{\mathbb{D}}$, Brandon Brown ${ }^{1,5}$, \\ Nourhan M. Aly 1,4 (D), Oliver Ezechi 1,6, Giuliana Florencia Abeldaño 1,7, Eshrat Ara 1,8 ${ }^{\mathbb{D}}$, \\ Martin Amogre Ayanore 1,9 $\mathbb{D}^{D}$, Passent Ellakany ${ }^{1,10}$, Balgis Gaffar 1,11 ${ }^{\mathbb{D}}$, Nuraldeen Maher A1-Khanati ${ }^{1,12} \mathbb{D}$, \\ Ifeoma Idigbe 1,6, Anthonia Omotola Ishabiyi 1,13 ${ }^{1}$, Mohammed Jafer 1,14,15, Abeedha Tu-Allah Khan 1,16, \\ Zumama Khalid 1,16 ${ }^{\mathbb{D}}$, Folake Barakat Lawal 1,17 $\mathbb{D}$, Joanne Lusher 1,18 $\mathbb{D}$, Ntombifuthi P. Nzimande 1,19 $\mathbb{D}$, \\ Bamidele Emmanuel Osamika 1,20(D), Mir Faeq Ali Quadri 1,21(D), Mark Roque 1,22 ${ }^{1}$, Ala'a B. Al-Tammemi ${ }^{1,23(\mathbb{D},}$ \\ Muhammad Abrar Yousaf 1,24 (D), Jorma I. Virtanen 1,25 (D), Roberto Ariel Abeldaño Zuñiga ${ }^{1,26}$ (D), \\ Joseph Chukwudi Okeibunor 1,27 (D) and Annie Lu Nguyen 1,28
}

Citation: Folayan, M.O.; Ibigbami, O.; El Tantawi, M.; Brown, B.; Aly, N.M.; Ezechi, O.; Abeldaño, G.F.; Ara E.; Ayanore, M.A.; Ellakany, P.; et al. Factors Associated with Financial Security, Food Security and Quality of Daily Lives of Residents in Nigeria during the First Wave of the COVID-19 Pandemic. Int. J. Environ. Res. Public Health 2021, 18, 7925. https:// doi.org/10.3390/ijerph18157925

Academic Editor: Abolfazl Mollalo

Received: 8 June 2021

Accepted: 18 July 2021

Published: 27 July 2021

Publisher's Note: MDPI stays neutral with regard to jurisdictional claims in published maps and institutional affiliations.

Copyright: (C) 2021 by the authors Licensee MDPI, Basel, Switzerland This article is an open access article distributed under the terms and conditions of the Creative Commons Attribution (CC BY) license (https:// creativecommons.org/licenses/by/ $4.0 /)$
1 Mental Health and Wellness Study Group, Obafemi Awolowo University, Ile-Ife 220282, Nigeria; oibigbami@oauife.edu.ng (O.I.); maha_tantawy@hotmail.com (M.E.T.); brandon.brown@medsch.ucr.edu (B.B.); nourhanovic@gmail.com (N.M.A.); oezechi@yahoo.co.uk (O.E.); gflorabeldano@gmail.com (G.F.A.); eshrataslam@gmail.com (E.A.); mayanore@uhas.edu.gh (M.A.A.); pellakany@iau.edu.sa (P.E.); bgosman@iau.edu.sa (B.G.); nuraldeen.alkhanati@gmail.com (N.M.A.-K.); ifeomagenia@yahoo.com (I.I.); paduatonia@yahoo.com (A.O.I.); dr.mjafer@gmail.com (M.J.); abeedha.sbs@pu.edu.pk (A.T.-A.K.); zumama.mphil.sbs@pu.edu.pk (Z.K.); folakemilawal@yahoo.com (F.B.L.); joanne.lusher@uws.ac.uk (J.L.); nzimandentombifuthi@gmail.com (N.P.N.); osamika.bamidele@lcu.edu.ng (B.E.O.); dr.faeq.quadri@gmail.com (M.F.A.Q.); markyroquedpa@gmail.com (M.R.); alaa.tammemi@med.unideb.hu (A.B.A.-T.); abrar.ms.zool@pu.edu.pk (M.A.Y.); jorma.virtanen@uib.no (J.I.V.); ariabeldanho@gmail.com (R.A.A.Z.); okeibunorj@who.int (J.C.O.); annie.nguyen@med.usc.edu (A.L.N.)

2 Department of Child Dental Health, Obafemi Awolowo University, Ile-Ife 220282, Nigeria

3 Department of Mental Health, Obafemi Awolowo University, Ile-Ife 220282, Nigeria

4 Department of Pediatric Dentistry and Dental Public Health, Faculty of Dentistry, Alexandria University, Alexandria 21527, Egypt

5 Department of Social Medicine, Population and Public Health, School of Medicine, University of California, Riverside, CA 92501, USA

6 Department of Clinical Sciences, Nigerian Institute of Medical Research, Lagos 101212, Nigeria

7 Institute for Research on Public Health, School of Medicine, University of Sierra Sur, Oaxaca 70805, Mexico

Government College for Women, Moulana Azad Road, Srinagar Kashmir, J\&K 190001, India

9 Department of Health Policy Planning and Management, University of Health and Allied Sciences, PMB 31 Ho, Ghana

10 Department of Substitutive Dental Sciences, College of Dentistry, Imam Abdulrahman Bin Faisal University, Dammam 31441, Saudi Arabia

11 Department of Preventive Dentistry, College of Dentistry, Imam Abdulrahman Bin Faisal University, Dammam 31441, Saudi Arabia

12 Department of Oral and Maxillofacial Surgery, Faculty of Dentistry, Syrian Private University, Damascus 36822, Syria

13 Centre for Rural Health, School of Nursing and Public Health, University of KwaZulu-Natal, Durban 4001, South Africa

14 Department of Preventive Dental Sciences, Faculty of Dentistry, Jazan University, Jazan 45142, Saudi Arabia

15 Department of Health Promotion, Faculty of Health, Medicine and Life Sciences, Maastricht University, 6200 MD Maastricht, The Netherlands

16 School of Biological Sciences, University of the Punjab, Quaid-i-Azam Campus, Lahore 54590, Pakistan

17 Department of Periodontology and Community Dentistry, University of Ibadan, Ibadan 200212, Nigeria

18 School of Health and Life Sciences, University of the West of Scotland, London E142BE, UK

19 Department of Economic and Human Geography, Faculty of Geosciences, University of Szeged, H-6722 Szeged, Hungary

20 Department of Psychology, Faculty of Environment, Management and Social Sciences, Lead City University, Ibadan 200255, Nigeria

21 Division of Dental Public Health, Department of Preventive Dentistry, Jazan University, Jazan 45142, Saudi Arabia 
22 Department of Maternity \& Childhood Nursing, College of Nursing, Taibah University, Madinah 42223, Saudi Arabia

23 Department of Family and Occupational Medicine, Faculty of Medicine, Doctoral School of Health Sciences, University of Debrecen, H-4032 Debrecen, Hungary

24 Institute of Zoology, University of the Punjab, Quaid-i-Azam Campus, Lahore 54590, Pakistan

25 Faculty of Medicine, University of Turku, FI-20014 Turku, Finland

26 Post Graduate School, University of Sierra Sur, Oaxaca 70800, Mexico

27 Research Development and Innovations, Assistant Regional Director Cluster, WHO Regional Office for Africa, Brazzaville BP 06, Congo

28 Department of Family Medicine, Keck School of Medicine, University of Southern California, Los Angeles, CA 91803, USA

* Correspondence: toyinukpong@yahoo.co.uk

\begin{abstract}
An online survey was conducted to identify factors associated with financial insecurity, food insecurity and poor quality of daily lives of adults in Nigeria during the first wave of the COVID-19 pandemic. The associations between the outcome (experience of financial loss, changes in food intake and impact of the pandemic on daily lives) and the explanatory (age, sex, education level, anxiety, depression, HIV status) variables were determined using logistic regression analysis. Of the 4439 respondents, $2487(56.0 \%)$ were financially insecure, $907(20.4 \%)$ decreased food intake and 4029 (90.8\%) had their daily life negatively impacted. Males (AOR:0.84), people who felt depressed (AOR:0.62) and people living with HIV -PLHIV- (AOR:0.70) had significantly lower odds of financial insecurity. Older respondents (AOR:1.01) had significantly higher odds of financial insecurity. Those depressed (AOR:0.62) and PLHIV (AOR:0.55) had significantly lower odds of reporting decreased food intake. Respondents who felt anxious (AOR:0.07), depressed (AOR: 0.48) and who were PLHIV (AOR:0.68) had significantly lower odds of reporting a negative impact of the pandemic on their daily lives. We concluded the study findings may reflect a complex relationship between financial insecurity, food insecurity, poor quality of life, mental health, and socioeconomic status of adults living in Nigeria during the COVID-19 pandemic.
\end{abstract}

Keywords: SARS-CoV-2; economic security; depression; anxiety; financial security; pandemic; HIV; AIDS; Nigeria

\title{
1. Introduction
}

The impact of COVID-19 pandemic varied between regions and countries. Food insecurity was worse in the most fragile regions of the world [1]. There were also substantial variations in anxiety and depression symptoms across countries during the COVID-19 lockdown [2,3]. In many countries around the world, many organisations and businesses had to shut down to maximise public safety resulting in significant loss of revenue. As a result, staff were laid off, work hours were reduced, salaries were cut, and furloughs were enacted in a bid to meet organisations' operating costs [4,5]. These types of market shocks have unequal consequences on the financial well-being of populations as a whole [6] with the impact varying between populations in-country thereby worsening the existing inequalities $[7,8]$. Women, young people, and adults aged 65 and older were more likely to be financially vulnerable during the pandemic while household heads with at least a tertiary education have a lower probability of being affected [9]. Working-age households may also face financial vulnerabilities and intersecting health, financial and other socioeconomic vulnerabilities [10].

It is likely that the impact of the economic shock caused by the pandemic will differ between populations [7]. For example, people living with HIV (PLHIV) may be more vulnerable to the COVID-19 pandemic's economic impact compared to those not living with HIV. This is because a high proportion of PLHIV work in industries that are more prone to COVID-19 disruptions; and PLHIV have disproportionately higher unemployment and food insecurity rates relative to the general population [11,12]. Among PLHIV in both 
low- and high-resource settings, food insecurity is more prevalent and well above the general population estimates, with women being most at risk [13]. Unemployment, drug misuse and worse physical and mental health status have also been associated with food insecurity for PLHIV [14]. Also, in times of economic crisis where jobs are not in abundance, PLHIV may be excluded from the labour market because of poor health status [15].

The economic shock caused by the pandemic may also affect men and women differently. Women's jobs are 1.8 times more vulnerable to the impact of the pandemic than men's jobs [16]. Women make up 39\% of global employment but account for $54 \%$ of overall job losses [16] with concerns that the pandemic may widen the existing gender inequality in job placements $[17,18]$. There also may be age, income and educational status differences in the impact of the pandemic. Younger populations in different countries are affected more though the impact across income groups is less clear and less consistent across countries [19]. However, there are few accessible publications on the disparity in the COVID-19 pandemic by educational status.

In addition to the negative impacts on financial and food security, the daily lives of many were disrupted with far reaching consequences for some. These impacts include the disruption of the medical supply chain and neglect of some health problems due to COVID-19 management prioritisation [20]. Schools, social events, travel, leisure, and entertainment have also been disrupted [21]. This impact had mental health consequences like anxiety and depression [22] that may be worse for people living in sub-Saharan Africa. Access to mental health care through telemedicine services may be challenging due to the low digital literacy, low smartphone penetration and limited internet connection which may make the provision of online mental health services a limited option in developing countries [23]. Depression and anxiety may also affect the use of telemedicine services thereby affecting daily lives due to poor access to healthcare during the pandemic [24].

Few studies have examined the impact of the COVID-19 pandemic on financial and food security in sub-Saharan Africa. Yet, sub-Saharan Africa is home to a many people living in poverty [25] who are likely to be negatively affected by the economic impact of the pandemic. The region is also home to many people with poor health. For example, the region is host to $67 \%$ of the population of PLHIV [26] and Nigeria is home to the second largest population of PLHIV [27]. Nigeria was also ranked 100 out of 113 nations in terms of food security [28]; and the country has a poor financial security profile. Lack of job opportunities is at the core of high poverty levels [29]. More than $80 \%$ of the population is employed in the informal economic sector and thus, dependent on daily income $[30,31]$. Between March and June 2020, the country instituted eight weeks of lockdown to control the pandemic and the total gross domestic product fell by $23 \%$ during that time [30]. The pandemic resulted in about 7 million newly poor people in 2020 [28]. In addition, the agri-food system gross domestic product also fell by $11 \%$ primarily due to restrictions on food services. Household incomes also fell by a quarter leading to a $9 \%$ point increase in the national poverty rate [30]. Understanding the impact of the pandemic on the financial vulnerability, food security and daily lives of people in countries in sub-Saharan Africa like Nigeria, may help policy makers to modify their programs and interventions to improve the current COVID-19 response by reaching out to persons most in need of food and financial support.

The aim of the present study was to identify factors associated with financial and food insecurity; as well as factors that affected the daily life of people in Nigeria during the first wave of the COVID-19 pandemic. Specifically, the study identified factors associated with financial loss and a decrease in food intake because of the COVID-19 pandemic. It was hypothesized that factors associated with financial loss and food insecurity can also be associated with the negative impact of the COVID-19 pandemic on the daily life of adults living in Nigeria. 


\section{Materials and Methods}

The data for this analysis was extracted from a cross-sectional multi-country survey. The international survey solicited information about mental health and wellness from a global convenience sample of adults aged 18 years and above from July to December 2020. Data were collected using an online survey platform (Survey Monkey, Momentive Inc.: San Mateo, CA, USA). Study participants for the global survey were recruited through respondent-driven sampling. Initial participants reached by the 45 data collectors, were asked to share the survey link with their contacts within their countries. The survey links were also posted on social media groups (Facebook, Twitter, and Instagram), network email lists and WhatsApp groups. Ethical approval for the study was obtained from the Human Research Ethics Committee at the Institute of Public Health of the Obafemi Awolowo University Ile-Ife, Nigeria (HREC No: IPHOAU/12/1557).

The data collection tool was initially developed for a study targeting a specific population in the United States and was consequently adapted and validated for global use [32]. The questionnaire took an average of $11 \mathrm{~min}$ to be completed and was administered in English. Study participants were asked to complete an anonymous, closed-ended questionnaire about how COVID-19 affected their wellness and well-being. The questionnaire enquired about the sociodemographic profile, COVID-19 impact on food intake and security, financial security and their daily life. Data of participants from Nigeria were extracted for the purpose of this study.

\subsection{Explanatory Variables}

Sociodemographic variables: The section on sociodemographic profile collected data on age, sex at birth and highest level of education attained (none, primary, secondary, college/university).

Mental health status: The questions were part of the Pandemic Stress Index assessing the psychosocial impact of COVID-19 [33]. The mental health status of the respondents was assessed by asking respondents to select from eight feelings that they may have experienced during COVID-19. Only two of the eight feelings assessed were used for this paper namely: anxiety and depression. Each were treated as dichotomous variables (yes/no).

HIV status: A question was also asked about HIV status. Respondents self-identified their HIV status as positive, negative, unknown, or indicated if they were unwilling to declare.

\subsection{Outcome Variables}

Impact of pandemic on financial security: Respondents were asked if they experienced a financial loss because of the COVID-19 pandemic and possible responses included, "yes", "no" or "I don't know". The question was adopted from the Multi-Center AIDS Cohort Study [34].

Impact of pandemic on food intake: The question enquiring about food security was adopted from the Pandemic Stress Index [33]. Respondents were asked if their food intake had changed during the pandemic. The possible responses were: "increased", "decreased", or "no change".

Impact of pandemic on daily lives: The impact of the pandemic on the daily lives of respondents was assessed by a single question. Respondents were asked: How much is/did COVID-19 negatively impact your day-to-day life? The response options were "extremely", "very much", "much", "a little" and "not at all". The responses were dichotomised to "had negative impact" (extremely, very much, much, a little) and "no negative impact" (not at all) [32].

\subsection{Data Analysis}

We performed multiple best-practice procedures to ensure the quality of our webbased survey data [35]. Each participant could only complete a single questionnaire through intellectual property address restrictions, though they could edit their answers 
freely until they choose to submit. The responses were downloaded from Survey Monkey as an SPSS Version 23.0 file (IBM SPSS Statistics for Windows, Armonk, NY: IBM Corp), cleaned and use for analysis. We identified and removed responses completed below seven minutes $(n=77)$; and those with incomplete data with respect to financial and food security questions and the question on COVID-19 impact on daily life $(n=252)$.

Descriptive analysis of the study variables was conducted. The test of associations between the outcome variables (impact of pandemic on financial security, food intake and daily lives) and the explanatory variables (age, sex, educational status, HIV status and mental health status), as well as with each other, were conducted using chi-square test (and $t$-test for age). Three logistic regression models were developed to identify the associations between the explanatory variables and each of the three outcome variables. The variables with a $p$ value of 0.5 or less were included in the models. Adjusted odds ratios (AORs) and $95 \%$ confidence intervals (CIs) were calculated. The model fitness was assessed using the Nagelkerke R2, the Hosmer Lemeshow goodness of fit test and the Omnibus test of model coefficients. Statistical significance was set at $5 \%$.

\section{Results}

There were 4439 respondents from Nigeria. Their mean age was $38.34(\mathrm{SD}=11.6)$ years, ranging from 18 to 85 years. The majority of respondents were females $(53.2 \%)$ and had tertiary education $(80.9 \%)$. There were $746(16.8 \%)$ respondents who reported being anxious, 389 ( $8.8 \%)$ felt depressed, 2487 (56.0\%) reported having financial insecurity, 907 $(20.4 \%)$ reported having a decrease in food intake during the pandemic and $4029(90.8 \%)$ had their daily lives negatively impacted by the pandemic. Also, $912(20.5 \%)$ respondents self-reported living with HIV.

As shown in Table 1, more respondents who had financial insecurity were older $(p<0.001)$, had no formal education, $(p=0.028)$, felt anxious $(p=0.041)$, depressed $(p<0.001)$ and were PLHIV $(p<0.001)$. Also, more respondents who reported a decrease in food intake had primary education $(p<0.001)$, felt anxious $(p<0.001)$, depressed $(p<0.001)$ and were PLHIV $(p<0.001)$. Similarly, more respondents who reported a negative impact of the pandemic on their daily life had primary school education $(p=0.002)$, felt anxious $(p<0.001)$, depressed $(p<0.001)$ and were PLHIV $(p=0.006)$.

As shown in Table 2, respondents who were male (AOR: 0.84; 95\% CI: 0.75-0.95; $p=0.005$ ), who felt depressed (AOR: 0.62; 95\% CI: 0.50-0.79; $p<0.001$ ) and PLHIV (AOR: 0.70 ; $95 \%$ CI: $0.59-0.83 ; p<0.001$ ) and had significantly lower odds of reporting financial insecurity. On the other hand, older respondents (AOR: 1.01; 95\% CI: 1.00-1.02; $p<0.001$ ) had significantly higher odds of reporting financial insecurity. 


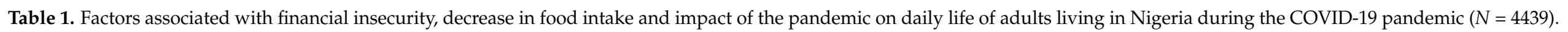

\begin{tabular}{|c|c|c|c|c|c|c|c|c|c|c|c|}
\hline \multirow[b]{2}{*}{ Variables } & \multirow[b]{2}{*}{ Total $n(\%)$} & \multicolumn{3}{|c|}{ Financial Insecurity } & \multicolumn{4}{|c|}{ Decrease in Food Intake } & \multicolumn{3}{|c|}{$\begin{array}{c}\text { Negative Impact of Pandemic on } \\
\text { Daily Life }\end{array}$} \\
\hline & & $\begin{array}{c}\text { Yes } \\
2487 \\
n(\%)\end{array}$ & $\begin{array}{c}\text { No } \\
1454 \\
n(\%)\end{array}$ & $\begin{array}{c}\text { Not Sure } \\
498 \\
n(\%)\end{array}$ & $p$ Value & $\begin{array}{c}\text { Yes } \\
907 \\
n(\%)\end{array}$ & $\begin{array}{c}\text { No } \\
3532 \\
n(\%)\end{array}$ & $p$ Value & $\begin{array}{c}\text { Yes } \\
4029 \\
n(\%\end{array}$ & $\begin{array}{c}\text { No } \\
410 \\
n(\%)\end{array}$ & $p$ Value \\
\hline $\begin{array}{c}\text { Age in years } \\
\text { Mean (SD) }\end{array}$ & $38.34(11.6)$ & $\begin{array}{l}39.77 \\
(12.0)\end{array}$ & $\begin{array}{l}37.67 \\
(11.3)\end{array}$ & $37.46(11.9)$ & $<0.001$ & $\begin{array}{l}38.37 \\
(11.6)\end{array}$ & $\begin{array}{l}38.33 \\
(11.6)\end{array}$ & 0.934 & $\begin{array}{l}38.43 \\
(11.6)\end{array}$ & $\begin{array}{l}37.45 \\
(11.6)\end{array}$ & 0.676 \\
\hline \multicolumn{12}{|l|}{ Sex at birth } \\
\hline Male & $2076(46.8)$ & $\begin{array}{c}1199 \\
(57.8)\end{array}$ & $\begin{array}{c}658 \\
(31.7)\end{array}$ & $\begin{array}{c}219 \\
(10.5)\end{array}$ & \multirow{2}{*}{0.083} & $\begin{array}{c}414 \\
(19.9)\end{array}$ & $\begin{array}{c}1662 \\
(80.1)\end{array}$ & \multirow{2}{*}{0.448} & $\begin{array}{l}1897 \\
(91.4)\end{array}$ & $\begin{array}{c}179 \\
(8.6)\end{array}$ & \multirow{2}{*}{0.185} \\
\hline Female & $2363(53.2)$ & $\begin{array}{c}1288 \\
(54.5)\end{array}$ & $\begin{array}{c}796 \\
(33.7)\end{array}$ & $\begin{array}{c}279 \\
(11.8)\end{array}$ & & $\begin{array}{c}493 \\
(20.9)\end{array}$ & $\begin{array}{c}1870 \\
(79.1)\end{array}$ & & $\begin{array}{r}2132 \\
(90.2)\end{array}$ & $\begin{array}{c}231 \\
(9.8)\end{array}$ & \\
\hline \multicolumn{12}{|c|}{ Highest educational level } \\
\hline None & $\begin{array}{c}48 \\
(1.1) \\
\end{array}$ & $\begin{array}{c}33 \\
(68.8) \\
\end{array}$ & $\begin{array}{c}8 \\
(16.7) \\
\end{array}$ & $\begin{array}{c}7 \\
(14.5) \\
\end{array}$ & \multirow{4}{*}{0.028} & $\begin{array}{c}17 \\
(35.4)\end{array}$ & $\begin{array}{c}31 \\
(64.6)\end{array}$ & \multirow{4}{*}{$<0.001$} & $\begin{array}{c}45 \\
(93.8) \\
\end{array}$ & $\begin{array}{c}3 \\
(6.2) \\
\end{array}$ & \multirow{4}{*}{0.002} \\
\hline Primary & $\begin{array}{c}84 \\
(1.9)\end{array}$ & $\begin{array}{c}44 \\
(52.3)\end{array}$ & $\begin{array}{c}26 \\
(31.0)\end{array}$ & $\begin{array}{c}14 \\
(16.7)\end{array}$ & & $\begin{array}{c}40 \\
(47.6)\end{array}$ & $\begin{array}{c}44 \\
(52.4)\end{array}$ & & $\begin{array}{c}83 \\
(98.8)\end{array}$ & $\begin{array}{c}1 \\
(1.2)\end{array}$ & \\
\hline Secondary & $715(16.1)$ & $\begin{array}{c}422 \\
(59.0)\end{array}$ & $\begin{array}{c}208 \\
(29.1)\end{array}$ & $\begin{array}{c}85 \\
(11.9)\end{array}$ & & $\begin{array}{c}163 \\
(22.8)\end{array}$ & $\begin{array}{c}552 \\
(77.2)\end{array}$ & & $\begin{array}{c}628 \\
(87.8)\end{array}$ & $\begin{array}{c}87 \\
(12.2)\end{array}$ & \\
\hline Tertiary & $3592(80.9)$ & $\begin{array}{l}1988 \\
(55.4)\end{array}$ & $\begin{array}{c}1212 \\
(33.7)\end{array}$ & $\begin{array}{c}392 \\
(10.9)\end{array}$ & & $\begin{array}{c}687 \\
(19.1)\end{array}$ & $\begin{array}{l}2905 \\
(80.9)\end{array}$ & & $\begin{array}{l}3273 \\
(91.1)\end{array}$ & $\begin{array}{l}319 \\
(8.9)\end{array}$ & \\
\hline \multicolumn{12}{|c|}{ Mental health status } \\
\hline \multicolumn{12}{|l|}{ Anxiety } \\
\hline No & $3693(83.2)$ & $\begin{array}{l}2066 \\
(55.9)\end{array}$ & $\begin{array}{l}1230 \\
(33.3)\end{array}$ & $\begin{array}{c}397 \\
(10.8)\end{array}$ & \multirow{2}{*}{0.041} & $\begin{array}{c}718 \\
(19.4)\end{array}$ & $\begin{array}{l}2975 \\
(80.6)\end{array}$ & \multirow{2}{*}{0.006} & $\begin{array}{r}3289 \\
(89.1)\end{array}$ & $\begin{array}{c}404 \\
(10.9)\end{array}$ & \multirow{2}{*}{$<0.001$} \\
\hline Yes & $746(16.8)$ & $\begin{array}{c}421 \\
(56.5)\end{array}$ & $\begin{array}{c}224 \\
(30.0)\end{array}$ & $\begin{array}{c}101 \\
(13.5)\end{array}$ & & $\begin{array}{c}189 \\
(25.3)\end{array}$ & $\begin{array}{c}557 \\
(74.7)\end{array}$ & & $\begin{array}{c}740 \\
(99.2)\end{array}$ & $\begin{array}{c}6 \\
(0.8)\end{array}$ & \\
\hline
\end{tabular}


Table 1. Cont.

\begin{tabular}{|c|c|c|c|c|c|c|c|c|c|c|c|}
\hline \multirow[b]{2}{*}{ Variables } & \multirow[b]{2}{*}{ Total $n(\%)$} & \multicolumn{3}{|c|}{ Financial Insecurity } & \multicolumn{4}{|c|}{ Decrease in Food Intake } & \multicolumn{3}{|c|}{$\begin{array}{c}\text { Negative Impact of Pandemic on } \\
\text { Daily Life }\end{array}$} \\
\hline & & $\begin{array}{c}\text { Yes } \\
2487 \\
n(\%)\end{array}$ & $\begin{array}{c}\text { No } \\
1454 \\
n(\%)\end{array}$ & $\begin{array}{c}\text { Not Sure } \\
498 \\
n(\%)\end{array}$ & $p$ Value & $\begin{array}{c}\text { Yes } \\
907 \\
n(\%)\end{array}$ & $\begin{array}{c}\text { No } \\
3532 \\
n(\%)\end{array}$ & $p$ Value & $\begin{array}{c}\text { Yes } \\
4029 \\
n(\%\end{array}$ & $\begin{array}{c}\text { No } \\
410 \\
n(\%)\end{array}$ & $p$ Value \\
\hline \multicolumn{12}{|l|}{ Depression } \\
\hline No & $4050(91.2)$ & $\begin{array}{c}2224 \\
(54.9)\end{array}$ & $\begin{array}{l}1376 \\
(34.0)\end{array}$ & $\begin{array}{c}450 \\
(11.1)\end{array}$ & $<0.001$ & $\begin{array}{c}785 \\
(19.4)\end{array}$ & $\begin{array}{l}3265 \\
(80.6)\end{array}$ & $<0.001$ & $\begin{array}{l}3653 \\
(90.2)\end{array}$ & $\begin{array}{l}397 \\
(9.8)\end{array}$ & $<0.001$ \\
\hline \multicolumn{12}{|l|}{ HIV infection status } \\
\hline Not living with HIV & $3527(79.5)$ & $\begin{array}{c}1923 \\
(54.5)\end{array}$ & $\begin{array}{r}1205 \\
(34.2)\end{array}$ & $\begin{array}{c}399 \\
(11.3)\end{array}$ & \multirow{2}{*}{$<0.001$} & $\begin{array}{c}626 \\
(17.7)\end{array}$ & $\begin{array}{c}2901 \\
(82.3)\end{array}$ & \multirow{2}{*}{$<0.001$} & $\begin{array}{l}3180 \\
(90.2)\end{array}$ & $\begin{array}{l}347 \\
(9.8)\end{array}$ & \multirow{2}{*}{0.006} \\
\hline Living with HIV & $912(20.5)$ & $\begin{array}{c}564 \\
(61.8)\end{array}$ & $\begin{array}{c}249 \\
(27.3)\end{array}$ & $\begin{array}{c}99 \\
(10.9)\end{array}$ & & $\begin{array}{c}281 \\
(30.8)\end{array}$ & $\begin{array}{c}631 \\
(69.2)\end{array}$ & & $\begin{array}{c}849 \\
(93.1)\end{array}$ & $\begin{array}{c}63 \\
(6.9)\end{array}$ & \\
\hline
\end{tabular}

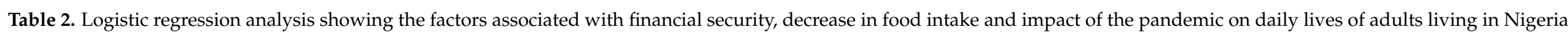
during the COVID-19 pandemic $(N=4439)$.

\begin{tabular}{|c|c|c|c|c|c|c|}
\hline \multirow{2}{*}{ Variables } & \multicolumn{2}{|c|}{ Financial Insecurity } & \multicolumn{2}{|c|}{ Decrease in Food Intake } & \multicolumn{2}{|c|}{ Negative Impact of Pandemic on Daily Life } \\
\hline & AOR $(95 \% \mathrm{CI})$ & $p$ Value & AOR $(95 \% \mathrm{CI})$ & $p$ Value & AOR $(95 \% \mathrm{CI})$ & $p$ Value \\
\hline Age in years & $1.01(1.00-1.02)$ & $<0.001$ & - & - & - & - \\
\hline Male (ref: not male) & $0.84(0.75-0.95)$ & 0.005 & $1.005(0.87-1.17)$ & 0.944 & $0.82(0.67-1.01)$ & 0.060 \\
\hline \multicolumn{7}{|l|}{ Highest educational level } \\
\hline None & 1.00 & - & 1.00 & - & 1.00 & - \\
\hline Primary & $2.06(0.97-4.38)$ & 0.060 & $0.59(0.28-1.23)$ & 0.159 & $0.18(0.02-1.79)$ & 0.143 \\
\hline Secondary & $1.52(0.80-2.88)$ & 0.202 & $1.36(0.72-2.55)$ & 0.341 & $1.25(0.37-4.25)$ & 0.721 \\
\hline Tertiary & $1.41(0.75-2.66)$ & 0.284 & $1.33(0.72-2.48)$ & 0.365 & $0.76(0.22-2.57)$ & 0.655 \\
\hline
\end{tabular}


Table 2. Cont.

\begin{tabular}{|c|c|c|c|c|c|c|}
\hline \multirow{2}{*}{ Variables } & \multicolumn{2}{|c|}{ Financial Insecurity } & \multicolumn{2}{|c|}{ Decrease in Food Intake } & \multicolumn{2}{|c|}{ Negative Impact of Pandemic on Daily Life } \\
\hline & AOR $(95 \% \mathrm{CI})$ & $p$ Value & AOR $(95 \% \mathrm{CI})$ & $p$ Value & AOR $(95 \% \mathrm{CI})$ & $p$ Value \\
\hline \multicolumn{7}{|l|}{ Mental health status } \\
\hline Yes (ref: No) & $1.06(0.90-1.26)$ & 0.466 & $0.87(0.72-1.06)$ & 0.164 & $0.08(0.03-0.17)$ & $<0.001$ \\
\hline \multicolumn{7}{|l|}{ Depression } \\
\hline Yes (ref: No) & $0.62(0.50-0.79)$ & $<0.001$ & $0.62(0.48-0.78)$ & $<0.001$ & $0.48(0.27-0.85)$ & 0.012 \\
\hline \multicolumn{7}{|l|}{ HIV status } \\
\hline $\begin{array}{c}\text { Living with HIV } \\
\text { (ref: Not living with HIV) }\end{array}$ & $0.70(0.59-0.83)$ & $<0.001$ & $0.55(0.46-0.67)$ & $<0.001$ & $0.68(0.50-0.92)$ & 0.012 \\
\hline Nagelkerke $\mathbf{R}^{2}$ & 0.020 & & 0.037 & & 0.070 & \\
\hline Hosmer Lemeshow goodness of fit test & 13.73 & 0.089 & 3.58 & 0.612 & 8.07 & 0.152 \\
\hline Omnibus test of model coefficients & 66.91 & $<0.001$ & 105.73 & $<0.001$ & 145.77 & $<0.001$ \\
\hline
\end{tabular}


Respondents who felt depressed (AOR: $0.62 ; 95 \% 0.48-0.78 ; p<0.001$ ) and who were PLHIV (AOR: $0.55 ; 95 \%$ CI: $0.46-0.67 ; p<0.001$ ) had significantly lower odds of reporting decreased food intake.

Also, respondents who felt anxious (AOR: $0.08 ; 95 \%$ CI: $0.03-0.17 ; p<0.001$ ), depressed (AOR: 0.48 ; 95\% CI: $0.27-0.85 ; p=0.012$ ) and who were PLHIV (AOR: $0.68 ; 95 \%$ CI: $0.50-0.92$; $p=0.012$ ) had significantly lower odds of reporting a negative impact of the pandemic on their daily life.

\section{Discussion}

The study findings underscore the complex relationships between factors associated factors associated with financial insecurity, decrease in food intake and the negative impact of COVID-19 among adults in Nigeria. First, the two factors that were associated with the three outcome variables were feeling depressed and living with HIV. Both factors reduced the odds of experiencing the financial insecurity, decrease in food intake and the negative impact of COVID-19 on the daily life of adults in Nigeria. Second, respondents who felt anxious had lower odds of reporting a negative impact of the epidemic on their daily lives. Third, socio-demographic variables were only associated with financial insecurity: financial insecurity significantly increased with older age, and the odds was lower for males when compared with non-males. Therefore, the study hypothesis is partially supported.

One of the strengths of the study is the large sample size making it possible to conduct robust data analysis. The study also provides one of the few findings on the impact of the COVID-19 pandemic on PLHIV in a country in sub-Saharan Africa; a region that is home to the majority of PLHIV [25].

Findings from the current study need to be considered in light of the following limitations. First, this is a cross-sectional study making it difficult to support causality. For example, it is not possible to determine the direction of the relationships of the factors associated with the outcome variables. Second, we also used self-reported measures of depression, anxiety and HIV status which are associated with high risk of social desirability bias. These forms of self-report may be more sensitive to identifying non-depressed, non-anxious and HIV negative individuals [36] because of the stigma associated with positive HIV and poor mental health status in sub-Saharan Africa [37-40]. Stigma may have resulted in under-reporting and an underestimation of the proportion of respondents who were depressed, anxious or PLHIV. There may also be the possibility of overestimating those who are HIV negative as a prior report from Nigeria noted that about $1.2 \%$ of adolescents living with HIV in the country report being HIV negative (this may or may or may not be applicable to adults) [35]. The sample is also a convenience sample with some associated challenges like the inability to generalise the result of the online survey to Nigeria as reflected by the skewness of the sample to those with tertiary education and possibly under-representation of those with low socioeconomic status; and a bias due to the exclusion of those who were able to fill the online questionnaire because of their access to the survey. This study may, however, be generalisable to the study population with tertiary education and may not be generalisable to settings with lower prevalence of HIV or a different profile of participants. The low values of the $\mathrm{R} 2$ of the models built for the logistic regression analysis supports our reflection that there might be other factors that may explain our study outcomes. The models, however, had good fits and outperformed the null models. In view of these limitations, the study is best considered exploratory and provides evidence to develop hypothesis for further studies.

Nevertheless, the study finding indicates that PLHIV are less prone to financial pressures, reductions in food intake and a negative impact of the epidemic on their daily life than do people not living with HIV. A plausible explanation may be that PLHIV lived a life of financial and food insecurity prior to the pandemic [41], and the magnitude of the new shock resulting from the pandemic may not have been as great for them. Also, PLHIV lives are majorly pre-occupied with addressing multiple vulnerabilities and thus, they have lived and adapted to a life of negative impacts prior to the pandemic [42,43]. It is 
therefore possible that during this pandemic, people not living with HIV have suffered more financial losses resulting from job loss [44], loss of or reduced wages [45] and investment losses [46,47]. These financial losses may have had a worse impact on food security among people not living with HIV, thereby having a larger impact on their daily life experiences. In effect, it appears that the life of PLHIV in Nigeria where less affected by the financial crisis, food crisis and other crises that may negatively impact the quality of life resulting from the pandemic through adaptation to a life of hardship [48] while these hardships are novel to people not living with HIV. Future studies need to explore the hypothesis posited here.

Financial insecurity is an emerging socioeconomic determinant of mental problems with indications that depression and anxiety are associated with higher risk of financial insecurity [49]. Similarly, financial and food insecurity increased anxiety and depression prior to $[50,51]$ and during the COVID-19 pandemic [52]. In the study population, only the feeling of depression was associated with financial and food insecurity; and it resulted in lower odds of a decrease in food intake contrary to prior findings. Anxiety was not associated with either financial or food insecurity in this study. Past studies had indicated that anxiety and depression may cause either an increase or a decrease in food intake [53,54]; and that racial and ethnic differences in the prevalence and severity of anxiety and depression $[55,56]$, there is no study accessible on racial and ethnic differences in the types of feeding disorder associated with anxiety and depression. This study may be a pointer to possible racial and ethnic differences in the way anxiety and depression affects food intake in different socio-cultural contexts.

Also, the finding that the negative impact of the COVID-19 on daily lives is less likely among those who felt anxious and depressed further complicates our findings. Prior studies had reported contrary findings: greater pandemic-related disruption in daily life were more likely in individuals with anxiety and depression symptoms [57]. Disruption of the daily lives of people by the pandemic also undermines the financial well-being of individuals and families [58], and this should circle back as a cause for anxiety or depression with a negative impact on food security and food intake. The impact of the pandemic on food intake, however, can vary between countries as there are a variety of COVID-19 related psychological changes that might have also affected food-related behaviours [59]. The reason for the findings in our study is unclear, though it does indicate a complex inter-relationship between these variables - mental health, financial security, decrease in food intake and perception of a negative impact of the pandemic on daily lives-that warrants further investigation. A plausibility is to explore the impact of culture and ethnicity as moderators of these relationships.

Men were less affected by financial insecurity, unlike prior studies that had indicated men were more affected by financial insecurity due to the perceived future associated risks [49]. The risk of other genders different from men facing higher financial insecurity due to the pandemic had been earlier reiterated. The informal economic sector, which was affected worse by the COVID-19 pandemic in Nigeria, is mainly run by women [60]. In the formal sector, women are more likely to be lower cadre staff, and thus are more likely to be laid off during the pandemic with the decrease in economic activities [60]. The entrenched role of women as care givers implies that they are less able to return fully to work during the pandemic when schools were closed as they had to provide care for the children [60]. the pandemic thereby further widened existing gender inequalities in the country. The risk of financial insecurity was also higher in the present study for older persons who are the major job holders in Nigeria (a lot of young persons do not have jobs [61,62]), thereby explaining why the study found older respondents were more likely to report financial insecurity.

\section{Conclusions}

We found a complex relationship between financial insecurity, decrease in food intake, mental health and HIV status and the negative daily life experiences of adults living in 
Nigeria during the first wave of the COVID-19 pandemic. Though some factors associated with the financial vulnerability and decrease in food intake of people in Nigeria during the pandemic were also associated with a negative impact of the COVID-19 pandemic on day-to-day life, the associations were not always in the same direction. Considering some of the limitations associated with the study design acknowledged here, further in-depth analyses to unravel these complexities may be warranted.

Author Contributions: M.O.F. conceptualized and designed the study, drafted the initial manuscript, and reviewed and revised the manuscript for important intellectual content. O.I. conducted the data analysis, reviewed and revised the manuscript for important intellectual content. M.E.T. and N.M.A. managed the data for the study, contributed extensively to the design of the study, reviewed and revised the manuscript for important intellectual content. M.E.T., B.B., O.E. and A.L.N. contributed extensively to the design of the study, reviewed and revised the manuscript for important intellectual content. G.F.A., E.A., M.A.A., P.E., B.G., N.M.A.-K., I.I., A.O.I., M.J., A.T.-A.K., Z.K., F.B.L., J.L., N.P.N., B.E.O., M.F.A.Q., M.R., A.B.A.-T., M.A.Y., J.I.V., R.A.A.Z. and J.C.O. reviewed and revised the manuscript for important intellectual content. All authors contributed to data collect and agreed to the read and approved the final manuscript.

Funding: ALN was supported by funding from the NIH/NIA (K01 AG064986-01). The contents of this paper do not necessarily represent the official views of the National Institutes of Health.

Institutional Review Board Statement: The study was conducted according to the guidelines of the Declaration of Helsinki and approved by the Human Research Ethics Committee at the Institute of Public Health of the Obafemi Awolowo University Ile-Ife, Nigeria (HREC No: IPHOAU/12/1557; 22 May 2020).

Informed Consent Statement: Informed consent was obtained from all subjects involved in the study.

Data Availability Statement: Data is available upon request from the corresponding author for this study.

Acknowledgments: We thank the study participants who have participated in this study.

Conflicts of Interest: The authors declare no conflict of interest. The authors alone are responsible for the views expressed in this article and they do not necessarily represent the views, decisions, or policies of the institutions with which they are affiliated.

\section{References}

1. Jafri, A.; Mathe, N.; Aglago, E.K.; Konyole, S.O.; Ouedraogo, M.; Audain, K.; Zongo, U.; Laar, A.K.; Johnson, J.; Sanou, D. Food availability, accessibility and dietary practices during the COVID-19 pandemic: A multi-country survey. Public Health Nutr. 2021, 24, 1798-1805. [CrossRef]

2. Ding, K.; Yang, J.; Chin, M.K.; Sullivan, L.; Demirhan, G.; Violant-Holz, V.; Uvinha, R.R.; Dai, J.; Xu, X.; Popeska, B.; et al. Mental Health among Adults during the COVID-19 Pandemic Lockdown: A Cross-Sectional Multi-Country Comparison. Int. J. Environ. Res. Public Health 2021, 18, 2686. [CrossRef]

3. Faulkner, J.; O’Brien, W.J.; McGrane, B.; Wadsworth, D.; Batten, J.; Askew, C.D.; Badenhorst, C.; Byrd, E.; Coulter, M.; Draper, N.; et al. Physical activity, mental health and well-being of adults during initial COVID-19 containment strategies: A multi-country cross-sectional analysis. J. Sci. Med. Sport 2021, 24, 320-326. [CrossRef]

4. McGuire, A.L.; Aulisio, M.P.; Daniel Davis, F.; Erwin, C.; Harter, T.D.; Jagsi, R.; Klitzman, R.; Macauley, R.; Racine, E.; Wolf, S.M.; et al. Ethical challenges arising in the COVID-19 pandemic: An overview from the Association of Bioethics Program Directors (ABPD) task force. Am. J. Bioethics 2020, 20, 15-27. [CrossRef]

5. Gabler, E.; Montague, Z.; Ashford, G. During a Pandemic, an Unanticipated Problem: Out-of-Work Health Workers. The New York Times, 2020. Available online: https://www.nytimes.com/2020/04/03/us/politics/coronavirus-health-care-workers-layoffs. html (accessed on 27 April 2021).

6. Botha, F.; de New, J.P.; de New, S.C.; Ribar, D.C.; Salamanca, N. Implications of COVID-19 labour market shocks for inequality in financial wellbeing. J. Popul. Econ. 2021, 34, 655-689. [CrossRef]

7. Kusuma, D.; Pradeepa, R.; Khawaja, K.I.; Hasan, M.; Siddiqui, S.; Mahmood, S.; Shah, S.M.; De Silva, C.K.; de Silva, L.; Gamage, M.; et al. Low uptake of COVID-19 prevention behaviours and high socioeconomic impact of lockdown measures in South Asia: Evidence from a large-scale multi-country surveillance programme. SSM Popul. Health 2021, 13, 100751. [CrossRef] [PubMed]

8. Prassl, A.; Boneva, T.; Golin, M.; Rauh, C. Inequality in the impact of the coronavirus shock: Evidence from real time surveys. IZA Discuss. Paper 2020, 189, 104245. 
9. Arellano, A.; Cámara, N. Financial Vulnerability of Households Facing COVID-19 Pandemia: A Global Perspective. BBVA Research. 4 September 2020. Available online: https:/ /www.bbvaresearch.com/en/publicaciones / financial-vulnerability-ofhouseholds-facing-covid-19-pandemia-a-global-perspective/ (accessed on 27 April 2021).

10. Mikol, J.; Keenan, K.; Kulu, H. Intersecting household-level health and socio-economic vulnerabilities and the COVID-19 crisis: An analysis from the UK. SSM-Popul. Health 2020, 12, 100628. [CrossRef]

11. Annequin, M.; Lert, F.; Spire, B.; Dray-Spira, R.; the VESPA2 Study Group. Has the employment status of people living with HIV changed since the early 2000s? AIDS 2015, 29, 1537-1547. [CrossRef]

12. Shiau, S.; Krause, K.D.; Valera, P.; Swaminathan, S.; Halkitis, P.N. The Burden of COVID-19 in People Living with HIV: A Syndemic Perspective. AIDS Behav. 2020, 24, 2244-2249. [CrossRef]

13. McKinsey and Company. COVID-19 and Gender Equality: Countering the Regressive Effects. 15 July 2020. Available online: https: //www.mckinsey.com/featured-insights/future-of-work/ covid-19-and-gender-equality-countering-the-regressive-effects (accessed on 13 May 2021).

14. Anema, A.; Vogenthaler, N.; Frongillo, E.A.; Kadiyala, S.; Weiser, S.D. Food insecurity and HIV/AIDS: Current knowledge, gaps, and research priorities. Curr. HIV/AIDS Rep. 2009, 6, 224-231. [CrossRef] [PubMed]

15. Peña Longobardo, L.M.; Oliva-Moreno, J. Differences in labour participation between people living with HIV and the general population: Results from Spain along the business cycle. PLoS ONE 2018, 13, e0195735. [CrossRef]

16. Belot, M.; Choi, S.; Tripodi, E.; van den Broek-Altenburg, E.; Jamison, J.C.; Papageorge, N.W. Unequal Consequences of COVID-19 across Age and Income: Representative Evidence from Six Countries. VoxEU. 24 July 2020. Available online: https:/ / voxeu.org/article/ unequal-consequences-covid-19-across-age-and-income (accessed on 13 May 2021).

17. Mahajan, D.; White, O.; Madgavkar, A.; Krishnan, M. Don't Let the Pandemic Set Back Gender Equality. Harv. Bus. Rev. 2020, 16.

18. Bloom, D.E.; McKenna, M.J.; Prettner, K. Global employment and decent jobs, 2010-2030: The forces of demography and automation. Int. Soc. Secur. Rev. 2019, 72, 43-78. [CrossRef]

19. Miller, F.A.; Young, S.B.; Dobrow, M.; Shojania, K.G. Vulnerability of the medical product supply chain: The wake-up call of COVID-19. BMJ Qual. Saf. 2021, 30, 331-335. [CrossRef]

20. Haleem, A.; Javaid, M.; Vaishya, R. Effects of COVID-19 pandemic in daily life. Curr. Med. Res. Pract. 2020, 10, 78-79. [CrossRef]

21. Castaldelli-Maia, J.M.; Marziali, M.E.; Lu, Z.; Martins, S.S. Investigating the effect of national government physical distancing measures on depression and anxiety during the COVID-19 pandemic through meta-analysis and meta-regression. Psychol. Med. 2021, 51, 881-893. [CrossRef]

22. Semo, B.; Frissa, S.M. The Mental Health Impact of the COVID-19 Pandemic: Implications for Sub-Saharan Africa. Psychol. Res. Behav. Manag. 2020, 13, 713-720. [CrossRef]

23. Laraia, B.A.; Siega-Riz, A.M.; Gundersen, C.; Dole, N. Psychosocial factors and socioeconomic indicators are associated with household food insecurity among pregnant women. J. Nutr. 2006, 136, 177-182. [CrossRef]

24. Bicaba, Z.; Brixiová, Z.; Ncube, M. Can extreme poverty in Sub-Saharan Africa be eliminated by 2030? J. Afr. Dev. 2017, 19, 93-110.

25. UNAIDS. Global HIV AIDS Statistics: 2020 Fact Sheet. 2020. Available online: https://www.unaids.org/en/resources/fact-sheet (accessed on 27 April 2021).

26. Global AIDS Monitoring 2020. Country Progress Report-Nigeria. Available online: https://www.ecoi.net/en/file/local/203836 3/NGA_2020_countryreport.pdf (accessed on 13 May 2021).

27. The Economist. Global Food Security Index 2020. Available online: https:/ / foodsecurityindex.eiu.com/index (accessed on 12 May 2021).

28. World Bank. Nigeria: Overview. Available online: https://www.worldbank.org/en/country/nigeria/overview (accessed on 13 May 2021).

29. Onwe, O. Role of the informal sector in development of the Nigerian economy: Output and employment approach. J. Econ. Dev. Stud. 2013, 1, 60-74.

30. Andam, K.; Edeh, H.; Oboh, V.; Pauw, K.; Thurlow, J. Impacts of COVID-19 on food systems and poverty in Nigeria. Adv. Food Secur. Sustain. 2020, 5, 145-173.

31. Obayelu, A.E.; Obayelu, O.A.; Bolarinwa, K.K.; Oyeyinka, R.A. Assessment of the Immediate and Potential Long-Term Effects of COVID-19 Outbreak on Socioeconomics, Agriculture, Security of Food and Dietary Intake in Nigeria. Food Ethics 2021, 6, 5. [CrossRef]

32. Nguyen, A.L.; Christensen, C.; Taylor, J.; Brown, B. Leaning on Community-Based Participatory Research to Respond During COVID-19. AIDS Behav. 2020, 24, 2773-2775. [CrossRef]

33. Harkness, A. The Pandemic Stress Index; University of Miami: Coral Gables, FL, USA, 2020.

34. MACS/WIHS Combined Cohort Study. Available online: https://statepi.jhsph.edu/mwccs/ (accessed on 15 May 2021).

35. Van Selm, M.; Jankowski, N.W. Conducting online surveys. Qual. Quant. 2006, 4, 435-456. [CrossRef]

36. Zarghami, M.; Taghizadeh, F.; Moosazadeh, M.; Kheradmand, M.; Heydari, K. Validity of self-reporting depression in the Tabari cohort study population. Neuropsychopharmacol. Rep. 2020, 40, 342-347. [CrossRef] [PubMed]

37. Mbonu, N.C.; van den Borne, B.; De Vries, N.K. Stigma of people with HIV/AIDS in Sub-Saharan Africa: A literature review. J. Trop. Med. 2009, 2009. [CrossRef] [PubMed] 
38. Dessauvagie, A.S.; Jörns-Presentati, A.; Napp, A.K.; Stein, D.J.; Jonker, D.; Breet, E.; Charles, W.; Swart, R.L.; Lahti, M.; Suliman, S.; et al. The prevalence of mental health problems in sub-Saharan adolescents living with HIV: A systematic review. Glob. Ment. Health 2020, 7, e29. [CrossRef] [PubMed]

39. Pantelic, M.; Shenderovich, Y.; Cluver, L.; Boyes, M. Predictors of internalised HIV-related stigma: A systematic review of studies in sub-Saharan Africa. Health Psychol. Rev. 2015, 4, 469-490. [CrossRef]

40. Arrey, A.E.; Bilsen, J.; Lacor, P.; Deschepper, R. Perceptions of stigma and discrimination in health care settings towards subSaharan African migrant women living with HIV/AIDS in Belgium: A qualitative study. J. Biosoc. Sci. 2017, 49, 578-596. [CrossRef]

41. Sholeye, O.O.; Animasahun, V.J.; Salako, A.A.; Oyewole, B.K. Household food insecurity among people living with HIV in Sagamu, Nigeria: A preliminary study. Nutr. Health 2017, 23, 95-102. [CrossRef] [PubMed]

42. Meng, Y.J.; Li, N.X.; Liu, C.J.; Chen, J.H.; Song, Y.C.; Qian, Z.S. Quality of life and hostile mentality trend of patients with HIV / AIDS in China. Public Health 2008, 122, 404-411. [CrossRef] [PubMed]

43. Rollins, N. Food insecurity-A risk factor for HIV infection. PLoS Med. 2007, 4, 1576-1577. [CrossRef]

44. Cassells, R.; Duncan, A.; Dockery, M.; Kiely, D.; Mavisakalyan, A. Potential job losses in the COVID-19 pandemic. Bankwest Curtin Econ. Cent. COVID-19 Res. Brief 2020, 2, 1-5.

45. Koczan, Z. Not All in This Together? Early Estimates of the Unequal Labour Market Effects of COVID-19. Available online: https://www.ebrd.com/publications/working-papers/not-all-in-this-together. (accessed on 19 July 2021).

46. Padhan, R.; Prabheesh, K.P. The economics of COVID-19 pandemic: A survey. Econ. Anal. Policy 2021, 70, 220-237. [CrossRef]

47. Chudik, A.; Mohaddes, K.; Pesaran, M.H.; Raissi, M.; Rebucci, A. Economic consequences of Covid-19: A counterfactual multi-country analysis. VoxEU. Org. 2020. Available online: https://voxeu.org/article/economic-consequences-covid-19-multicountry-analysis. (accessed on 19 July 2021).

48. Ibrahim, F.; Anderson, J.; Bukutu, C.; Elford, J. Social and economic hardship among people living with HIV in London. HIV Med. 2008, 9, 616-624. [CrossRef]

49. Kopasker, D.; Montagna, C.; Bender, K.A. Economic insecurity: A socioeconomic determinant of mental health. SSM-Popul. Health 2018, 6, 184-194. [CrossRef]

50. Kolovos, S.; Zavala, G.A.; Leijen, A.S.; Melgar-Quiñonez, H.; van Tulder, M. Household food insecurity is associated with depressive symptoms: Results from a Mexican population-based survey. Food Sec. 2020, 12, 407-416. [CrossRef]

51. Jones, A.D. Food insecurity and mental health status: A global analysis of 149 countries. Am. J. Prev. Med. 2017, 53, 264-273. [CrossRef]

52. Fang, D.; Thomsen, M.R.; Nayga, R.M., Jr. The association between food insecurity and mental health during the COVID-19 pandemic. BMC Public Health 2021, 21, 607. [CrossRef]

53. Rutters, F.; Nieuwenhuizen, A.G.; Lemmens, S.G.; Born, J.M.; Westerterp-Plantenga, M.S. Acute stress-related changes in eating in the absence of hunger. Obesity 2009, 17, 72-77. [CrossRef]

54. Simmons, W.K.; Burrows, K.; Avery, J.A.; Kerr, K.L.; Bodurka, J.; Savage, C.R.; Drevets, W.C. Depression-Related Increases and Decreases in Appetite: Dissociable Patterns of Aberrant Activity in Reward and Interoceptive Neurocircuitry. Am. J. Psychiatry 2016, 173, 418-428. [CrossRef]

55. Bailey, R.K.; Mokonogho, J.; Kumar, A. Racial and ethnic differences in depression: Current perspectives. Neuropsychiatr. Dis. Treat. 2019, 15, 603-609. [CrossRef]

56. Williams, D.R.; González, H.M.; Neighbors, H.; Nesse, R.; Abelson, J.M.; Sweetman, J.; Jackson, J.S. Prevalence and distribution of major depressive disorder in African Americans, Caribbean blacks, and non-Hispanic whites: Results from the National Survey of American Life. Arch. Gen. Psychiatry 2007, 64, 305-315. [CrossRef] [PubMed]

57. Sherman, A.C.; Williams, M.L.; Amick, B.C.; Hudson, T.J.; Messias, E.L. Mental health outcomes associated with the COVID-19 pandemic: Prevalence and risk factors in a southern US state. Psychiatry Res. 2020, 293, 113476. [CrossRef] [PubMed]

58. Friedline, T.; Chen, Z.; Morrow, S. Families' Financial Stress \& Well-Being: The Importance of the Economy and Economic Environments. J. Fam. Econ. Issues 2021, 42, 34-51.

59. Janssen, M.; Chang, B.P.I.; Hristov, H.; Pravst, I.; Profeta, A.; Millard, J. Changes in Food Consumption During the COVID-19 Pandemic: Analysis of Consumer Survey Data from the First Lockdown Period in Denmark, Germany, and Slovenia. Front. Nutr. 2021, 8, 635859. [CrossRef]

60. Akpan, U. Covid-19 in Nigeria: A Gendered Perspective. SOAS University of London. Available online: https://study.soas.ac uk/covid-19-in-nigeria-a-gendered-perspective/ (accessed on 17 May 2021).

61. Olurinola, I.O.; Fadayomi, T. Youth Labour Market Outcomes in Nigeria: Evidence from National Labour Market Survey. Covenant J. Bus. Soc. Sci. 2013, 5, 1-25.

62. Oyebode, A. Nigeria: The Economic Impact of COVID-19 on the Youth. The Africa Report.com. 2020. Available online: https:/ / www.theafricareport.com/36412/nigeria-what-is-most-important-is-we-put-millions-of-young-people-in-jobsand-quickly / (accessed on 15 May 2021). 